\title{
PLASTIC DESIGN AND SEISMIC RESPONSE OF KNEE BRACED FRAMES
}

\author{
Maria Antonietta Conti ${ }^{1}$, Luigi Mastrandrea ${ }^{2}$ and Vincenzo Piluso ${ }^{3, *}$ \\ ${ }^{1}$ Department of Civil Engineering, University of Salerno, via Ponte Don Melillo, 84084 Fisciano (SA), Italy \\ ${ }^{2}$ Department of Civil Engineering, University of Salerno, via Ponte Don Melillo, 84084 Fisciano (SA), Italy \\ ${ }^{3}$ Full Professor, Department of Civil Engineering, University of Salerno, via Ponte Don Melillo, \\ 84084 Fisciano (SA), Italy \\ *(Corresponding author: E-mail: v.piluso@unisa.it)
}

Received: 15 July 2008; Accepted: 20 July 2008

\begin{abstract}
In this paper a design methodology aiming at the development of a collapse mechanism of global type for seismic resistant knee braced frames is presented. The proposed methodology is based on the assumption that the beam, brace and knee sections are known, while the column sections constitute the unknowns of the design problem. The design requirements are derived by means of the kinematic theorem of plastic collapse. In particular, column sections are obtained by imposing that the mechanism equilibrium curve corresponding to the global mechanism has to lie below those corresponding to all the undesired mechanisms within a displacement range compatible with the local ductility supply of knee elements.

The proposed design procedure has been implemented in a computer program and applied to design some knee braced frames. Successively, static and dynamic non-linear analyses have been carried out aiming at the evaluation of the performance of the designed braced frames in terms of collapse mechanism developed under seismic forces, energy dissipation capacity and global and local ductility demands.
\end{abstract}

Keywords: Knee braced frames; collapse mechanism; capacity design; limit design; non-linear analyses; equivalent moment; global ductility; local ductility

\section{INTRODUCTION}

Knee braced frames (KBFs) constitute an innovative bracing solution. They are obtained by stiffening moment resisting frames by means of diagonal braces which are not connected to beam-to-column joints, but are restrained by means of short elements, namely "knee", which span, at each storey, between the column and the beam (Figure 1). The brace allows to limit interstorey drifts, while the knee element dissipates the earthquake input energy by means of transverse cyclic deformations in shear and/or bending. From this point of view, KBFs combine a lateral stiffness similar to that of concentrically braced frames (CBFs) with a ductile behaviour similar to that of eccentrically braced frames (EBFs). The main advantage with respect to EBFs is that damage is concentrated in a secondary member which can be easily replaced after destructive earthquakes.

The purpose of this study is to illustrate a design methodology able to guarantee a collapse mechanism of global type for KBFs. As universally recognised, the global mechanism is the main goal of the design process of a seismic resistant structure. In fact, among all the possible mechanisms, it allows the maximum global ductility and energy dissipation capacity. Even though modern codes provide the designer with the awareness of the importance of the collapse mechanism typology, the suggested design rules are only able to avoid soft storey mechanisms, without developing the global one. This is the case of member hierarchy criteria, proposed for different structure typologies, which are not able to grasp the distribution of internal actions to be developed to assure a collapse mechanism of global type. 
In addition, all code member dimensioning rules are focused on the capacity design principles, while local ductility supplies are assured by means of technological suggestions, such as the use of web stiffeners in the case of members subjected predominantly to shear action (like links in EBFs). Conversely, there are no explicit rules to limit local ductility demands, i.e. to avoid the premature fracture of the dissipative zones.

The proposed design methodology is aimed at satisfying both these design requirements. The targets are represented on one hand by the development of a global mechanism for KBFs, leading to a satisfactory global ductility, and on the other hand by the local ductility control. This is obtained by means of the limit analysis, which allows to define appropriate design conditions and contemporary provides useful tools to account for local ductility demands. This methodology has already been developed in the case of moment resisting frames (Mazzolani and Piluso [1]) and eccentrically braced (Mastrandrea et al. [2]), providing satisfactory results, so that it is proposed as a general design approach for seismic resistant structures.

With reference to KBFs, in Figure 1 the possible collapse mechanisms for KBFs are depicted; among these the global one is to be achieved because it maximizes the energy dissipation capacity and the global ductility supply. These mechanisms, involving the knee elements as dissipative zones, are named type "a" mechanisms. With reference to the portal KB-frame, other mechanism typologies, namely type "b" and type "c", are depicted in Figure 2 (Conti [3]). Their pattern of yielding is characterised by the involvement of undesired non-dissipative zones, such as columns and beams, so that they are responsible of reduced energy dissipation capacity when compared to type " $a$ " mechanisms. The aim of the proposed procedure is to provide a global mechanism of "a" type for multi-storey KB-frames.

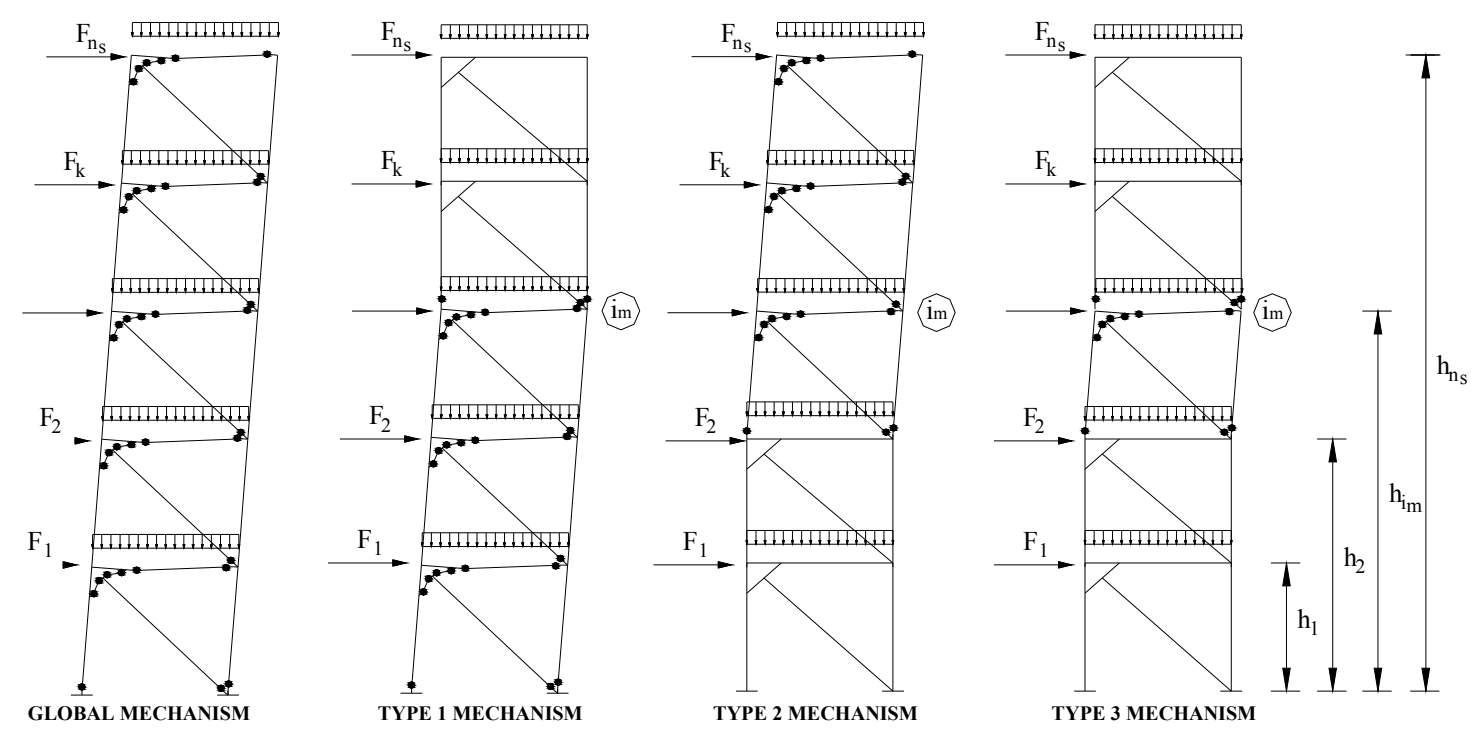

Figure 1. Collapse Mechanisms for a KB-Frame - Type "a" Mechanism 


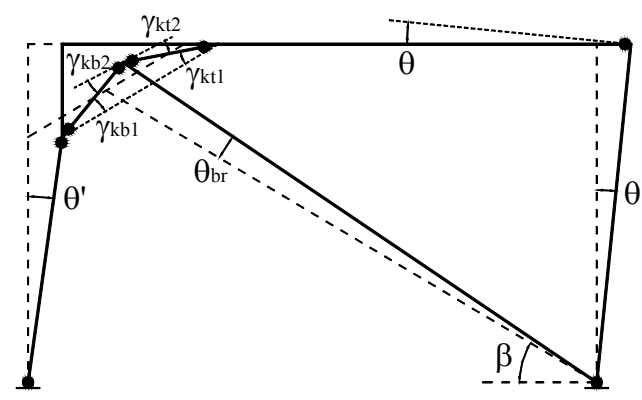

type "b"

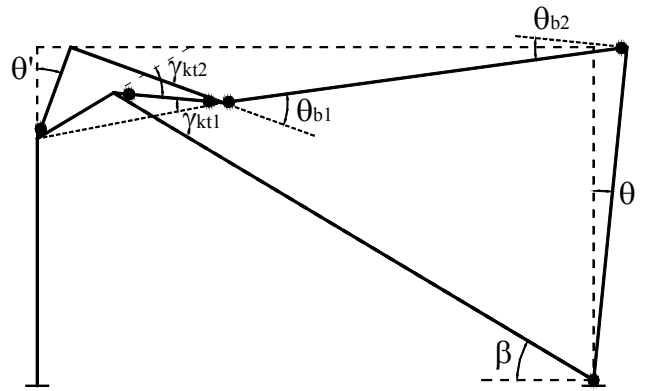

type "c"

Figure 2. Collapse Mechanisms for a KB-Frame - Type "b" and Type "c" Mechanisms

In the proposed design methodology, it is assumed that the beam, brace and knee sections are known, while the column sections constitute the unknowns of the design problem. In particular according to capacity design, knee elements, which represent dissipative members, are sized considering the internal actions due to the code specified seismic horizontal forces, while the brace sections are designed to prevent buckling under the maximum internal actions which the fully yielded and strain-hardened knee elements are able to transmit. In addition, the beam sections are designed to resist vertical loads. Therefore, the unknowns of the design problem are constituted by the column sections which have to be defined so that the mechanism equilibrium curve corresponding to the global mechanism has to lie below those corresponding to all the undesired mechanisms within a displacement range compatible with the local ductility supply. It means that, according to the upper bound theorem, the global mechanism is the only mechanism which can be developed within a displacement range compatible with the local ductility supplies (Mazzolani and Piluso [4]).

In this paper, the procedure has been developed with reference to one bay KB-frames where the brace connections can be either continuous or pinned. For different KBF layouts the same procedure can be applied by properly accounting for the actual geometrical configuration.

\section{BEHAVIOUR OF KNEE ELEMENTS}

The study of the plastic behaviour of knee elements shows several analogies with links in EBFs. In fact, both knee elements and links are subjected to transverse cyclic deformations, so that they are characterised by relevant shear actions (short elements). As a consequence, similarly to the case of links, the ultimate behaviour of knee elements is influenced by their length. In fact, the interaction between shear force and bending moment becomes more and more relevant as the member length increases, up to a value for which shear action becomes almost negligible (long elements). In particular, since the diagonal subdivides the knee element into two different parts, the whole dissipative member can be compared with two links, each one of length equal to $e / 2$, being the brace-to-knee joint generally located at midspan. Starting from this consideration, the well known link classification (Kasai and Popov [5]) can be adopted also for knee elements, so that it is possible to recognise three knee typologies: short knees, intermediate knees and long knees (Conti et al. [6]). In particular, the plastic interaction domain provided by Neal [7] is assumed:

$$
\left(\frac{|M|-M_{f}}{M_{p}-M_{f}}\right)^{2}+\left(\frac{V}{V_{p}}\right)^{2}=1 \quad \text { for } M_{f} \leq|M| \leq M_{p}
$$




$$
V=V_{p} \text { for }|M| \leq M_{f}
$$

being $M_{p}$ and $V_{p}$ the plastic moment resistance and the plastic shear resistance of the cross section, and $M_{f}$ the contribution of the flanges to the plastic moment of the section. The interpretation of testing results is usually based on the evaluation of the plastic shear resistance as:

$$
V_{p}=0.6 f_{y}\left(d-2 t_{f}\right) t_{w}
$$

where $f_{y}$ is the yield stress, $d$ the knee section depth, $t_{f}$ and $t_{w}$ are the thicknesses of the flange and of the web, respectively, according to the American practice.

In addition, strain-hardening effects are accounted for on the basis of the experimental tests provided by Clement [8], which reveal an increase of the plastic resistance equal to $70 \%$ in average. This result is quite similar to the case of links in EBFs, for which, on the basis of several experimental tests performed worldwide (Popov and Engelhardt [9]; Ozaki et al. [10]), a 50\% increase of the resistance is recognised, so that an overstrength factor of 1.5 is usually adopted in design practice (CEN [11]). Therefore, within capacity design methodologies, this overstrength has to be properly accounted for in predicting the internal actions transferred by the link to the non-dissipative zones of the structure, aiming to their dimensioning so that yielding cannot occur before links develop their ultimate resistance.

Following these issues, on the basis of the similarity between knee elements and links, an overstrength factor has to be adopted also in the case of KBFs. In fact, the dimensioning of non-dissipative zones cannot neglect this contribution, due to the consequent amplification of the internal actions transferred by knee elements. With this aim, an amplification factor of 1.7 can be adopted for KBFs, as suggested by Clement [8]. As a consequence, in this paper the ultimate interaction domain is obtained by means of an homothetic expansion of the plastic one using the amplification factor $1.7\left(V_{u}=1.7 V_{p}, M_{u}=1.7 M_{p}, M_{f u}=1.7 M_{f}\right)$. In order to justify this kind of approach, it is useful to remark that, due to the discussed similarity, the well known ultimate conditions for links (Engelhardt and Popov [12]) can be extended also to knee elements, leading to the following relationships:

$$
\begin{aligned}
& \left\{\begin{array}{c}
V_{u}=\psi V_{p} \\
M_{u}=\frac{\psi}{2} e / 2 V_{p} \text { for } e / 2 \leq 1.6 \frac{M_{p}}{V_{p}}
\end{array}\right. \\
& \left\{\begin{array}{l}
M_{u}=\psi M_{p} \\
V_{u}=2 \frac{M_{u}}{e / 2}
\end{array} \quad \text { for } e / 2 \geq 3.0 \frac{M_{p}}{V_{p}}\right.
\end{aligned}
$$

while a linear interpolation, depending on the $e / 2$ value, is necessary in the case of intermediate knee elements. The coefficient $\psi$ is the overstrength factor related to the strain-hardening, which assumes the value 1.5 in the case of links of EBFs and the value 1.7 in the case of knee elements as previously discussed. In Figure 3 a comparison with the proposed homothetic formulation is depicted, showing a good agreement. This kind of approach has been already used and validated in the case of links of EBFs (Mastrandrea et al. [13]). 
In particular, the KB-frames analysed in this paper are characterised by short knees, i.e. knees for which $e / 2 \leq 1.6 M_{p} / V_{p}$ (Kasai and Popov [5]). The chosen scheme is characterised by the following properties: the diagonal axis intersects the beam-column joint; diagonal is connected to the knee midspan section, so that the brace and the knee have the same inclination and, generally, they are not perpendicular. With reference to the collapse mechanism of a portal frame (Figure 4), the following relationships between the plastic rotation of each member and the plastic rotation of the column can be obtained:

$\theta_{b r}=\frac{H-e \operatorname{sen} \beta}{2 H-e \operatorname{sen} \beta} \theta$

$\gamma_{k b 1}=\frac{H}{e \operatorname{sen} \beta} \theta \quad \gamma_{k b 2}=\frac{2 H(H-e \operatorname{sen} \beta)}{e \operatorname{sen} \beta(2 H-e \operatorname{sen} \beta)} \theta$

$\gamma_{k t 1}=\frac{H}{e \operatorname{sen} \beta} \theta \quad \gamma_{k t 2}=\frac{2 H^{2}}{e \operatorname{sen} \beta(2 H-e \operatorname{sen} \beta)} \theta$

$\theta_{b}=\frac{L}{L-d} \theta$

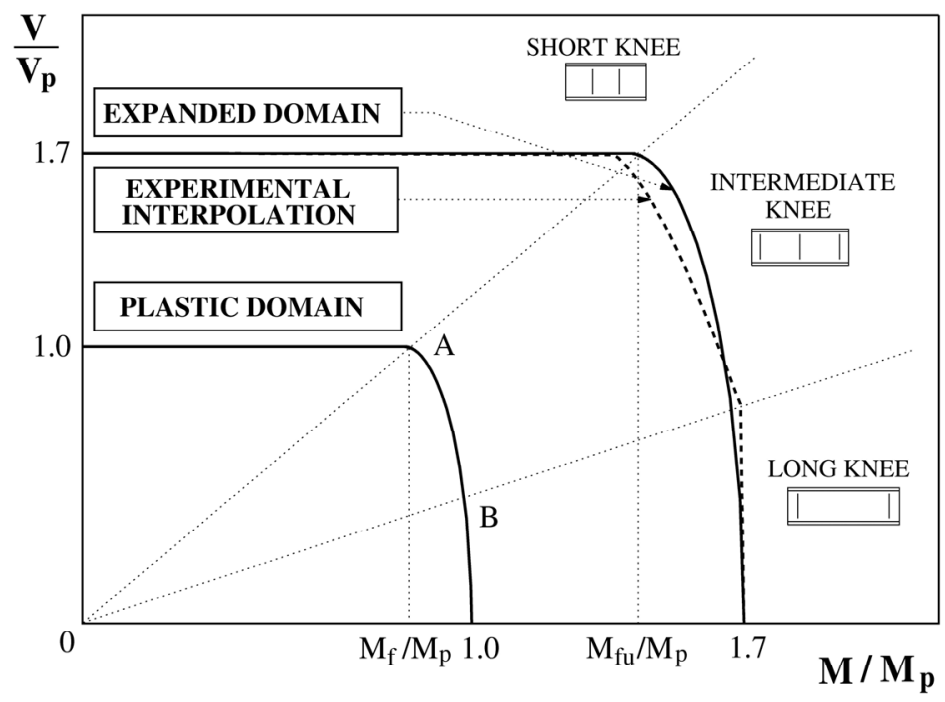

Figure 3. Plastic $V-M$ Interaction Diagram and Comparison between

Ultimate Interaction Domains.

Regarding the position $d$ of the plastic hinge developed within the beam span (Figure 4), due to the superposition of vertical loads and horizontal forces, the maximum bending moment is attained at the abscissa (Mazzolani and Piluso [1]):

$$
\begin{aligned}
& d=e \cos \beta \quad \text { for } q \leq q_{\lim }=\frac{4 M_{b}}{(L-e \cos \beta)^{2}} \\
& d=L-2 \sqrt{\frac{M_{b}}{q}} \text { for } q>q_{\lim }
\end{aligned}
$$

being $M_{b}$ the plastic moment of the beam. 


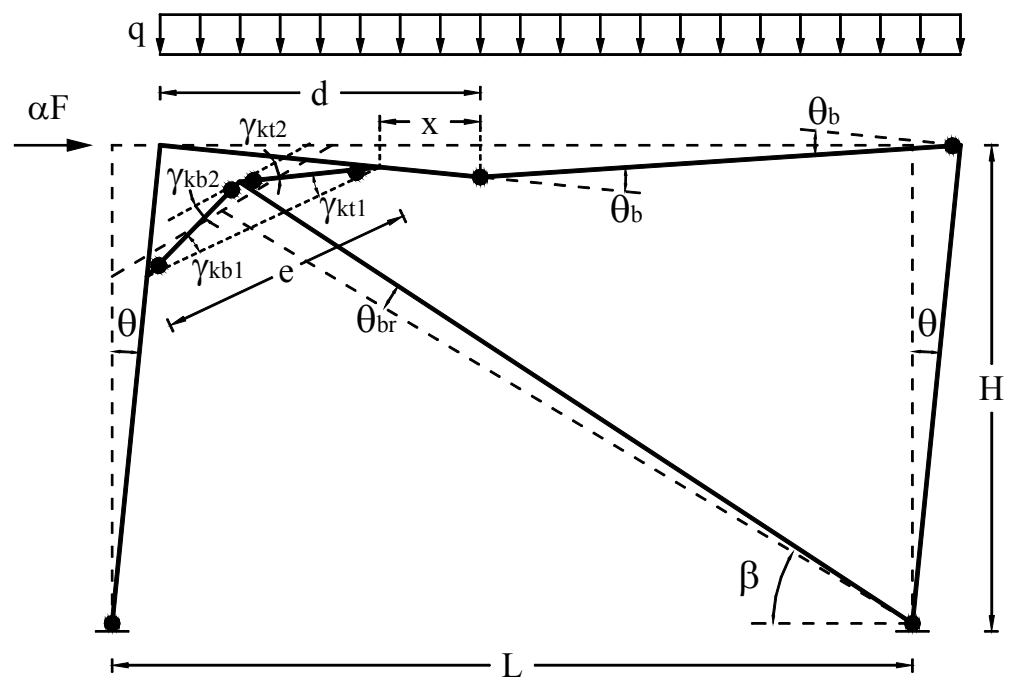

Figure 4. Collapse Mechanisms for a KB-Frame - Type "a" Mechanism

Furthermore, with reference to the collapse mechanism of a multi-storey KB-frame (Figure 5), it is useful to point out that the plastic rotation of braces provided by Eq. 6 is valid only for the first storey $\left(\theta_{b r .1}\right)$. In fact, it is easy to recognize that the plastic rotations of diagonals of second and upper storeys are affected by the rigid rotation $\theta$ of the column. The following relationships are obtained:

$$
\theta_{b r . i}=\frac{h_{i}}{2 h_{i}-e_{i} \operatorname{sen} \beta_{i}} \theta \quad i=2,3, \ldots, n_{s}
$$

being $h_{i}$ the interstorey height, $e_{i}$ the length of the knee and $\beta_{i}$ the inclination of the brace of the $i$ th storey, respectively.

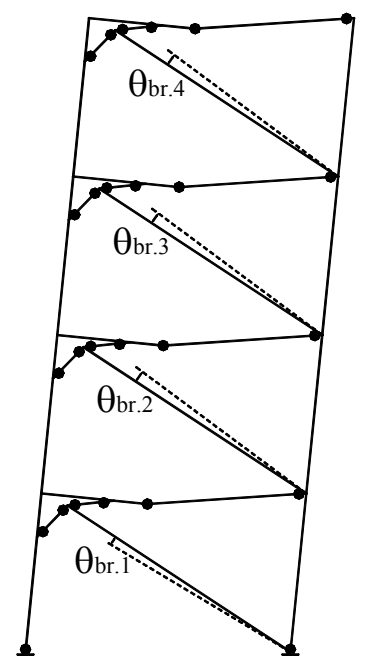

Figure 5. Global Collapse Mechanisms for a KB-Frame

Eqs. 7-8 show that plastic rotations of the two knees (bottom and top) are different. Furthermore, the rotation values are also different at the two ends within a single knee. In the case of dominant shear behaviour (short knee, i.e. $e / 2 \leq 1.6 M_{p} / V_{p}$ similarly to Kasai and Popov [5]) the previously discussed rotations represent angular distortions under the plastic shear action $V_{p}$. Nevertheless, a member subjected to uniform shear action is theoretically characterised by a uniform angular distortion along its length. Therefore, the circumstance for which different values of the rotation arise at the ends of the member leads to the conclusion that the deformation is partially due to the 
shear action and partially due to the bending moment. In other words, even a short knee is subjected to moment-shear interaction, which is yet neglected in Eq. 2. For this reason, in the case of short knees an average value of the plastic deformation for each knee portion can be approximately adopted:

$$
\begin{aligned}
& \bar{\gamma}_{k b}=\frac{\gamma_{k b 1}+\gamma_{k b 2}}{2}=\frac{H(4 H-3 e \operatorname{sen} \beta)}{e \operatorname{sen} \beta(4 H-2 e \operatorname{sen} \beta)} \theta \\
& \bar{\gamma}_{k t}=\frac{\gamma_{k t 1}+\gamma_{k t 2}}{2}=\frac{H(4 H-e \operatorname{sen} \beta)}{e \operatorname{sen} \beta(4 H-2 e \operatorname{sen} \beta)} \theta
\end{aligned}
$$

and it can be assumed that the ultimate behaviour of the member is governed only by the shear force. It is useful to note that, starting from Eqs. 13-14, the following value is obtained for the mean value of the plastic deformation of the entire knee element:

$$
\bar{\gamma}_{k}=\frac{\bar{\gamma}_{k b}+\bar{\gamma}_{k t}}{2}=\frac{H}{e \operatorname{sen} \beta} \theta
$$

Eq. 15 is particularly useful, because it provides, at least within the rigid-plastic analysis, a measure of the plastic engagement of the knee element as a function of the lateral displacement, i.e. the column rotation, of the entire structure.

Conversely, in the case of an intermediate knee, moment-shear interaction becomes significant so that plastic deformations provided by Eqs. 7-8 actually represent a combination of plastic shear deformation and plastic moment rotation. An analytical procedure to compute the ultimate resistances and the plastic deformations of intermediate knee elements, accounting for the interaction between bending moment and shear force, has been developed by the Authors within the framework of plastic design (Conti et al. [6]).

However, in this paper reference is made to the case of short knees. As a conclusion, with reference to the proposed KBF layout, Eqs. 6, 9, 12, 13 and 14 constitute useful tools for limit design applications, and they are applied within the design procedure described in the following Sections.

\section{THE PROPOSED DESIGN METHODOLOGY}

The aim of the proposed design methodology is to allow the dimensioning of KB-frames developing at collapse a mechanism of the global type. Therefore, the design requirements are derived to avoid the partial mechanisms depicted in Figure 1 (type 1, type 2 and type 3 mechanisms) and the less dissipative mechanism typologies depicted in Figure 2.

To this scope, the knee elements are recognised as dissipative zones, so that the design procedure is aimed to assure the engagement of all of them in the collapse mechanism. On the contrary, all other members have to remain in elastic range, except for the first order columns and diagonals (if not pinned at the ground) which participate to the kinematic mechanism.

The procedure is based on the assumption that knee, beam and brace cross sections are known, since they are designed on the basis of the code specified seismic actions as in the following clarified, while sections of the columns constitute the unknowns of the design problem. The design conditions are defined by imposing that the mechanism equilibrium curve corresponding to the 
global mechanism has to lay below those corresponding to all the undesired mechanisms within a displacement range compatible with the local ductility supply. According to the upper bound theorem, these conditions guarantee that the true collapse mechanism of the structure is represented by the global failure mode.

\subsection{Design of Dissipative Zones, Beams and Braces}

According to capacity design, knee sections are designed on the basis of internal actions arising from the seismic forces prescribed by the codes. In particular, knee elements are dimensioned with reference to a simplified scheme assuming that the axial internal forces of braces of KBF are approximately equal to those of braces of a concentrically braced frame with the same geometry. Therefore, the axial force of the brace of the generic storey is evaluated as:

$$
N_{d . i}=\frac{Q_{i}}{\cos \beta_{i}}
$$

where $Q_{\mathrm{i}}$ is the seismic shear force of the $i$ th storey and $\beta_{\mathrm{i}}$ is the brace inclination. The design value of shear force of the knee portion is obtained by means of the approximate translational equilibrium equation of the knee-to-brace joint in the direction orthogonal to the knee:

$$
V_{\text {knee.Sd.i }}=\frac{N_{d . i}}{2} \operatorname{sen} 2 \beta_{i}
$$

This value underestimates the actual shear forces of the knee elements. Therefore, it is suggested the application to the value provided by Eq. 17 of an amplification factor equal to 1.25.

Similarly, the design axial force of the brace is obtained by maximising Eq. 17. In fact, being non-dissipative zones, braces have to be dimensioned on the basis of the maximum internal actions that dissipative zones are able to transmit, which means that the design axial force of each brace is obtained by assuming that the corresponding knee is yielded and strain-hardened up to its ultimate resistance, so that it is equal to:

$$
N_{d . S d . i}=\frac{2 V_{\text {knee.u. } i}}{\operatorname{sen} 2 \beta_{i}}
$$

where $V_{\text {knee.u. } i}=1.7 V_{\text {knee.p. } i}$ is the ultimate shear force of the knee portion accounting for strain-hardening (Clement [8]). The brace sections are designed to prevent buckling under the axial force given by Eq. 18 .

Finally, the beam sections are designed in order to resist to vertical loads.

\subsection{Equilibrium Curves of Analysed Mechanisms}

Where not specified, symbols adopted in the following formulas are referred to the notation reported in Appendix.

With reference to Figure 1, it is possible to recognise that, for a virtual rotation value $d \theta$ of columns and diagonals involved by the mechanism, the total internal virtual work is provided by the following relationship: 


$$
W_{l}=\left[\operatorname{tr}\left(\mathbf{C}^{\mathbf{T}} \mathbf{R}_{\mathbf{C}}\right)+\mathbf{B}_{\mathbf{r}}^{\mathbf{T}} \mathbf{R}_{\mathbf{d}}+2 \mathbf{B}^{\mathbf{T}} \mathbf{R}_{\mathbf{b}}+\mathbf{K}_{\mathbf{k n}}^{\mathbf{T}} \mathbf{R}_{\mathbf{k n}}\right] d \theta
$$

where the symbol $t r$ denotes the trace of the matrix.

The external work, due to vertical and horizontal loads, is expressed by the following equation:

$$
W_{e}=\left(\alpha \mathbf{F}^{\mathbf{T}} \mathbf{s}+\mathbf{q}^{\mathbf{T}} \mathbf{D}_{\mathbf{v}}\right) d \theta
$$

where $\alpha$ is the kinematically admissible multiplier.

By means of the virtual work principle, the kinematically admissible multiplier of horizontal forces, for the mechanisms depicted in Figure 1, is given by:

$$
\alpha=\frac{\operatorname{tr}\left(\mathbf{C}^{\mathbf{T}} \mathbf{R}_{\mathbf{C}}\right)+\mathbf{B}_{\mathbf{r}}^{\mathbf{T}} \mathbf{R}_{\mathbf{d}}+2 \mathbf{B}^{\mathbf{T}} \mathbf{R}_{\mathbf{b}}+\mathbf{K}_{\mathbf{k n}}^{\mathbf{T}} \mathbf{R}_{\mathbf{k n}}-\mathbf{q}^{\mathbf{T}} \mathbf{D}_{\mathbf{v}}}{\mathbf{F}^{\mathbf{T}} \mathbf{S}}
$$

The second-order work due to vertical loads is provided by the following relationship (Mazzolani \& Piluso, 1997):

$$
W_{v}=\mathbf{V}^{\mathbf{T}} \mathbf{s} \frac{\delta}{H_{0}} d \theta
$$

therefore, the slope of mechanism equilibrium curve is given by:

$$
\gamma=\frac{1}{H_{0}} \frac{\mathbf{V}^{\mathbf{T}} \mathbf{s}}{\mathbf{F}^{\mathbf{T}} \mathbf{s}}
$$

By means of Eqs. 21 and 23, the mechanism equilibrium curve is expressed by:

$$
\alpha_{c}=\alpha-\gamma \delta
$$

The following notation will be used to denote the parameters of the equilibrium curve of the considered mechanisms:

- $\alpha^{(g)}$ and $\gamma^{(g)}$ are, respectively, the kinematically admissible multiplier of horizontal forces and the slope of the softening branch of the $\alpha-\delta$ curve, corresponding to the global type mechanism;

- $\alpha_{i m}{ }^{(t)}$ and $\gamma_{i m}{ }^{(t)}$ have the same meaning of the previous symbols, but they are referred to the $i_{\mathrm{m}}$ th mechanism of $t$ th type.

In the case of global type mechanism (Figure 1), as all the storeys participate to the collapse mechanism, the shape vector of the horizontal displacements is given by $\mathbf{s}^{(\mathbf{g})}=\mathbf{h}$. In addition, all knee elements are involved so that the kinematically admissible multiplier is given by:

$$
\alpha^{(g)}=\frac{\mathbf{M}_{\mathbf{c} 1}^{\mathbf{T}} \mathbf{I}+\mathbf{B}_{\mathbf{r}}^{\mathbf{T}} \mathbf{R}_{\mathbf{d}}^{(\mathbf{g})}+2 \mathbf{B}^{\mathbf{T}} \mathbf{R}_{\mathbf{b}}^{(\mathbf{g})}+\mathbf{K}_{\mathbf{n}}^{\mathbf{T}} \mathbf{R}_{\mathbf{k n}}^{(\mathbf{g})}-\mathbf{q}^{\mathbf{T}} \mathbf{D}_{\mathbf{v}}^{(\mathbf{g})}}{\mathbf{F}^{\mathbf{T}} \mathbf{s}^{(\mathbf{g})}}
$$

where I denotes the unity vector of order $n_{c}$. 
Furthermore, because all the storeys participate to the global mechanism, $H_{0}$ is equal to $h_{n s}$, and the slope $\gamma^{(g)}$ is obtained from Eq. 23 for $\mathbf{s}=\mathbf{s}^{(g)}$ and $H_{0}=h_{n s}$.

With reference to the $i_{m}$ th mechanism of type 1 , the shape vector of the horizontal displacements can be written as:

$$
\mathbf{s}_{\mathbf{i}_{\mathbf{m}}}^{(\mathbf{1})}=\left\{h_{1}, h_{2}, h_{3}, \ldots, h_{i_{m}}, h_{i_{m}}, h_{i_{m}}\right\}^{T}
$$

where the first element equal to $h_{i m}$ corresponds to the $i_{m}$ th component. The kinematically admissible multiplier corresponding to the $i_{m}$ th mechanism of type 1 is given by:

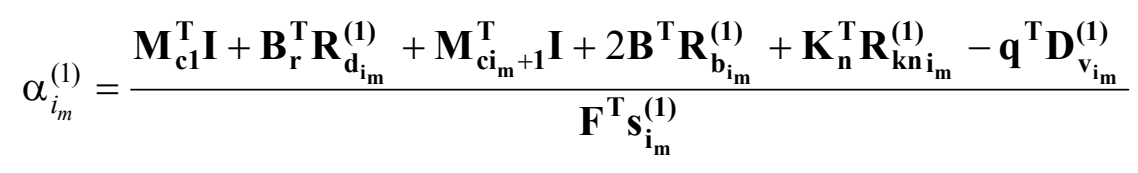

In addition, only the first $i_{m}$ storeys participate to the collapse mechanism, so that $H_{0}=h_{i m}$. As a consequence, the slope of the mechanism equilibrium curve is still computed through Eq. 23, but assuming $\mathbf{s}=\mathbf{s}_{\mathbf{i m}}{ }^{(\mathbf{1})}$ and $H_{0}=h_{\text {im }}$.

The expressions of the kinematically admissible multipliers $\alpha_{i m}{ }^{(2)}$ and $\alpha_{i m}{ }^{(3)}$, and of the slopes $\gamma_{i m}{ }^{(2)}$ and $\gamma_{i m}{ }^{(3)}$, of the mechanism equilibrium curves corresponding to type 2 and type 3 mechanisms, respectively, can be obtained by means of the same procedure.

\subsection{Design Conditions for Failure Mode Control}

According to the upper bound theorem of limit design, the cross-sections of columns have to be defined so that the kinematically admissible horizontal force multiplier corresponding to the global type mechanism is the minimum among all the kinematically admissible multipliers.

This condition is sufficient to guarantee the desired mechanism only in the case of rigid-plastic behaviour of the structural material, so that no displacements are developed until the collapse mechanism is reached. Conversely, the actual behaviour is elastoplastic, and it is characterised by significant displacements before the collapse mechanism is completely activated. These displacements are responsible of second order effects which cannot be neglected in the design process. Therefore, to account for second order effects, the design conditions have to be defined by imposing that the mechanism equilibrium curve corresponding to the global type mechanism has to lie below those corresponding to all the other mechanisms within a displacements range compatible with the plastic deformation capacity of members (Figure 6). This represents the extension of the kinematic theorem of plastic collapse to the mechanism equilibrium curve concept. Consequently, the design conditions are provided by the following equations:

$$
\begin{gathered}
\alpha^{(g)}-\gamma^{(g)} \delta_{u} \leq \alpha_{i_{m}}^{(t)}-\gamma_{i_{m}}^{(t)} \delta_{u} \\
\text { for } i_{m}=1,2, \ldots, n_{s} \text { and } t=1,2,3 .
\end{gathered}
$$




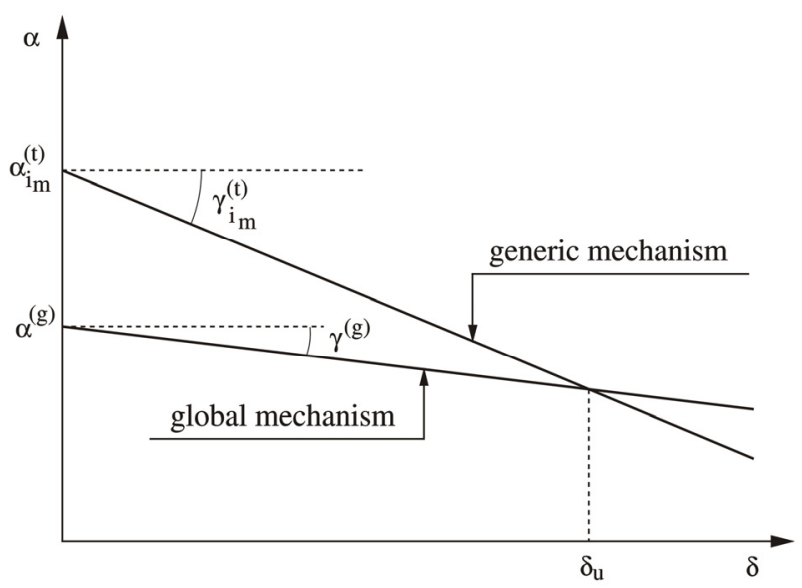

Figure 6. Mechanism Equilibrium Curves

It is useful to note that the displacement $\delta_{u}$ has to be compatible with the local ductility supply of dissipative zones and it assumes the meaning of design displacement, so that the proposed design methodology leads both to failure mode and local ductility control.

Substituting the values of $\alpha^{(g)}, \gamma^{(g)}, \alpha_{i m}{ }^{(1)}$ and $\gamma_{i m}{ }^{(1)}$ in Eq. 28, the conditions to be satisfied to avoid type 1 mechanisms are obtained. In particular, the following design conditions are obtained $\left(i_{m}=1\right.$, $\left.2, \ldots, n_{s}\right)$ :

$$
\begin{aligned}
& \frac{\mathbf{M}_{\mathbf{c} 1}^{\mathbf{T}} \mathbf{I}+\mathbf{B}_{\mathbf{r}}^{\mathbf{T}} \mathbf{R}_{\mathbf{d}}^{(\mathbf{g})}+2 \mathbf{B}^{\mathbf{T}} \mathbf{R}_{\mathbf{b}}^{(\mathrm{g})}+\mathbf{K}_{\mathbf{n}}^{\mathbf{T}} \mathbf{R}_{\mathbf{k n}}^{(\mathrm{g})}-\mathbf{q}^{\mathbf{T}} \mathbf{D}_{\mathbf{v}}^{(\mathrm{g})}}{\mathbf{F}^{\mathbf{T}} \mathbf{s}^{(\mathbf{g})}}-\frac{\mathbf{V}^{\mathbf{T}} \mathbf{s}^{(\mathrm{g})}}{\mathbf{F}^{\mathbf{T}} \mathbf{s}^{(\mathbf{g})}} \frac{\delta_{u}}{h_{n_{s}}} \leq
\end{aligned}
$$

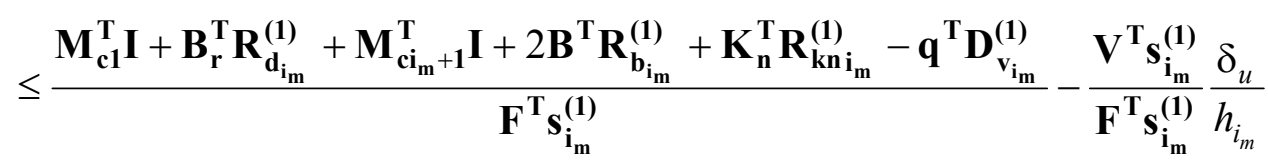

In the same way, the conditions to be satisfied in order to avoid type 2 and type 3 mechanisms can also be obtained. The plastic section moduli of columns, which constitute the unknowns of the design problem, can be determined satisfying simultaneously these $3 n_{s}$ design conditions.

Moreover, it is necessary to guarantee the development of type "a" mechanism, rather than type "b" or type "c". This is made by means of additional design rules, which are still based on the application of the kinematic theorem of plastic collapse. In particular, by comparing the collapse configurations depicted in Figure 2 and Figure 4, it is easy to recognise that the deformed shapes are similar (i.e. the same top-sway displacement is obtained for each structure if the same $\theta$ column rotation is considered), so that the external virtual work due to an horizontal force $F$ is given by:

$$
W_{e . F}=\alpha F \delta=\alpha F H \theta
$$

independently of the mechanism typology. Therefore, by applying the virtual works principle, the following relationship is obtained for the horizontal multiplier $\alpha(t=a, b, c)$ :

$$
W_{i}^{(t)}=W_{e . q}^{(t)}+W_{e . F}^{(t)}=W_{e . q}^{(t)}+\alpha^{(t)} F H \theta
$$


$\alpha^{(t)}=\frac{W_{i}^{(t)}-W_{e . q}^{(t)}}{F H \theta}$

According to the kinematic theorem of plastic collapse, the requirements to be fulfilled to avoid undesired collapse mechanisms are obtained by imposing that the kinematically admissible horizontal force multiplier corresponding to type "a" collapse mechanism is less than those corresponding to type "b" and type "c" collapse mechanisms. Therefore, the following equations have to be satisfied:

$$
\alpha^{(a)} \leq \alpha^{(b)} \quad \text { and } \alpha^{(a)} \leq \alpha^{(c)}
$$

leading to the required design criteria, respectively:

$$
\begin{aligned}
& M_{c} \geq \frac{H-e \operatorname{sen} \beta}{H+e \operatorname{sen} \beta}\left[M_{b} \frac{L+d}{L-d}-M_{d} \frac{e \operatorname{sen} \beta}{2 H-e \operatorname{sen} \beta}\right] \\
& M_{c} \geq \frac{e \operatorname{sen} \beta}{H-e \operatorname{sen} \beta}\left\{M_{d} \frac{H-e \operatorname{sen} \beta}{2 H-e \operatorname{sen} \beta}-\frac{V_{u} H}{2 \operatorname{sen} \beta}-M_{b}\left[\frac{H(H+e \operatorname{sen} \beta)}{e \operatorname{sen} \beta(H-e \operatorname{sen} \beta)}-\frac{L+d}{L-d}\right]+\frac{q L(L-d)}{2}\right\}
\end{aligned}
$$

which are obtained by means of the plastic rotations depicted in Figure 2 (Conti et al. [6]). With reference to a multi-storey $\mathrm{KBF}$, in order to avoid mechanisms characterised by the alternation of type "a", type "b" and type "c" configurations at different levels, it is sufficient to check that Eqs. 34-35 are satisfied for each storey of the structural system.

Therefore, taking into account all the previously discussed conditions and requirements, handling the previous formulations and pointing out attention on technological conditions, similarly to the case of moment-resisting frames (Mazzolani and Piluso [1]), it is possible to define a design algorithm which allows, by means of an iterative process, to obtain the design solution in terms of column plastic moments (Conti et al. [14]). Due to the presence of the axial forces, these moments represent a reduced value if compared to the resistance provided in simple bending.

Then, the design column sections are obtained by coupling, for each column, the determined plastic moment with the axial force occurring in the collapse state. This axial force can be estimated by means of simplified equilibrium equations. In particular, the column axial force is provided by the vertical translational equilibrium equation of column-to-knee joint and is equal to:

$$
N_{c . i}=\sum_{j=i}^{n_{s}} V_{k n e e . u . j} \cos \beta_{j}
$$

Aiming at the evaluation of its accuracy, the proposed design procedure has been implemented into a computer program and applied to dimension an adequate number of KBFs whose seismic response has been investigated by means of non-linear static and dynamic analyses. In particular, reference is made to the case of short knees, which is the most frequent, due to the length of such members. In next Sections the results of these analyses are presented and discussed. 


\section{NON-LINEAR KNEE MODEL: THE EQUIVALENT MOMENT CONCEPT}

In order to carry out non-linear analyses for KBFs, the post-elastic behaviour of each element has to be properly modelled. To this scope, due to their shear plastic involvement, the geometrical inclination of the knees introduces some difficulties in their non-linear modelling. In fact, plastic shear deformations for each knee portion are the result of both horizontal and vertical displacements occurring at the member ends. Several computer programs, as for example DRAIN-2DX (which has been used to carry out dynamic non-linear analyses), do not provide the user with an adequate predefined element in their library for modelling a non-linear behaviour in shear, particularly in the case of inclined members.

Therefore, to easily simulate the actual non-linear behaviour of a knee element it is useful to define an equivalent element with plastic hinges in simple bending at its ends. This is obtained by imposing the equivalence between the internal work developed by each actual knee portion and the internal work corresponding to the simplified theoretical model.

The internal virtual work developed, for example, by the bottom knee portion is equal to:

$$
L_{i . k b}=\int_{0}^{e / 2} V \gamma_{k b} d z=V_{p} \bar{\gamma}_{k b} \frac{e}{2}
$$

where $\bar{\gamma}_{k b}$ is provided by Eq. 13. The internal virtual work developed by the equivalent model in simple bending is given by:

$$
L_{i . k b}=2 M_{e q . p} \bar{\gamma}_{k b}
$$

being $M_{\text {eq.p }}$ the so defined equivalent moment in plastic conditions. The equivalence between Eq. 37 and Eq. 38 provides the following expression:

$$
M_{e q . p}=V_{p} \frac{e}{4}
$$

which is easily obtained also in the case of the top knee portion. The same procedure can be extended to the ultimate conditions, when the strain-hardening effect influences the behaviour of the member. To this scope, Eqs. 37-38 are applied considering the shear resistance $V_{u}=1.7 V_{p}$, so that the ultimate equivalent moment is obtained:

$$
M_{e q . u}=V_{u} \frac{e}{4}=1.7 M_{e q . p}
$$

The Eqs. 39-40 allow to deal with a model in which the shear behaviour of knee elements is taken into account by means of an equivalent element exhibiting flexural behaviour, easier to be handled. However, a validation of the approach has been performed by means of a complete finite element model. In particular, a knee element has been studied by means of STRAUS7 computer program. The cross section is represented by an HEA 200 standard profile. It has been subdivided in several areas, both for the flanges and for the web, while the fillet of the web-to-flange connection has been neglected. An elastic-perfectly plastic law has been assigned to each of them, by assuming a yield stress equal to $275 \mathrm{MPa}$. The length of the member is equal to $100 \mathrm{~cm}$, and the edge restraints have been modelled as rigid. In order to simulate the interaction with the brace element, a rigid body has been assigned to the middle of the knee element with a length equal to $20 \mathrm{~cm}$ representing the 
interaction zone due to the brace. Along this part, a monotonically increasing transversal load has been applied, so that the non-linear force-displacement curve has been carried out. In Figure 7 and Figure 8 the FEM model and the distribution of the Von Mises ideal stresses at first yielding are depicted. It is useful to note that at first yielding an ideal stress equal to $f_{y}$ is almost reached on the whole web panel (Figure 8).

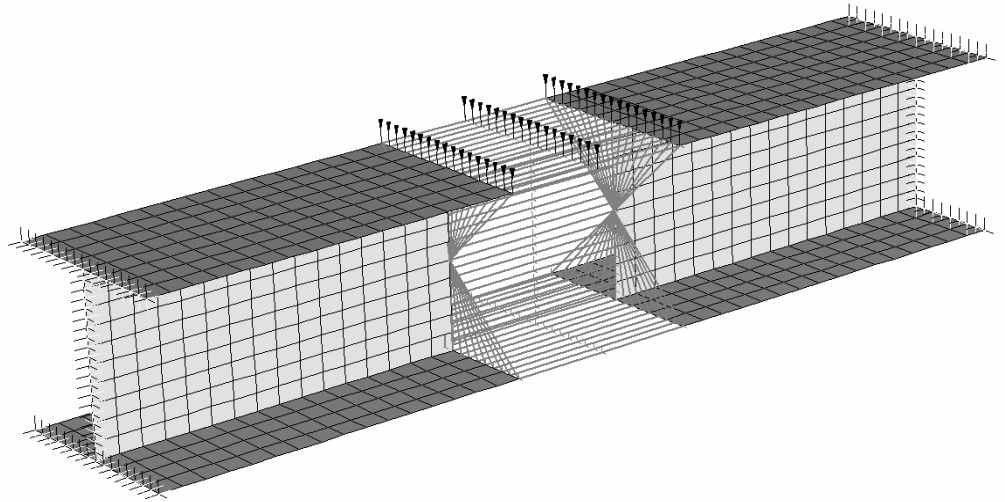

Figure 7. STRAUS7 FEM Model

The described complete FEM model has been compared with the equivalent model in simple bending previously introduced. To this scope, a scheme geometrically equal to the previous one has been analysed by means of SAP2000 computer program. In this case, the knee element has been modelled by means of three beam-column elements, two representing the knee portions and one representing the rigid body in the middle. The post-elastic behaviour has been taken into account by means of plastic hinges in simple bending at the ends. The plastic hinges have been calibrated with an elastic perfectly-plastic moment-rotation curve, by means of the Eq. 39, in which the plastic shear resistance calculated by means of the Eq. 3 is equal to $185.76 \mathrm{kN}$. In this way, the comparison between the two models is performed under the same constitutive law.

In Figure 9 a comparison between the force-displacement curves of the two models is depicted. It shows a satisfactory agreement, providing the validation of the equivalent model in simple bending. In fact, the scatters between the two curves are very small, both in elastic and plastic ranges. It is useful to note that the difference in the transition zone between elastic and plastic behaviour is due to the fact that the non-linear analysis carried out by means of SAP2000 is based on a lumped plasticity approach, while in the case of STRAUS7 the spreading of plasticity is step-by-step developed as far as the displacement increases.

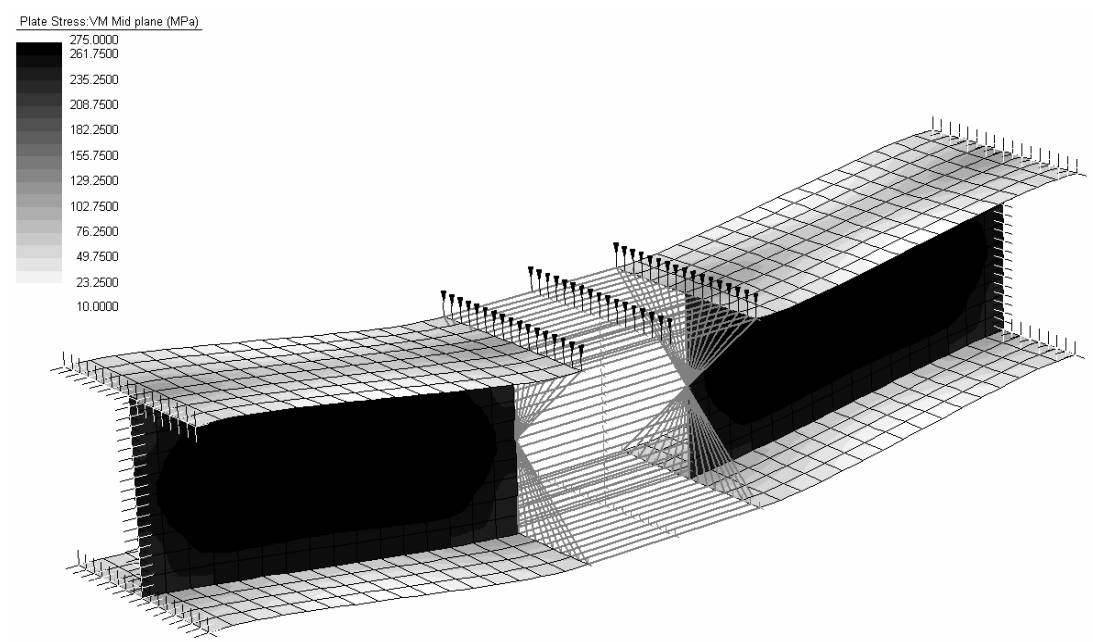

Figure 8. STRAUS7stress Map at the First Yielding 


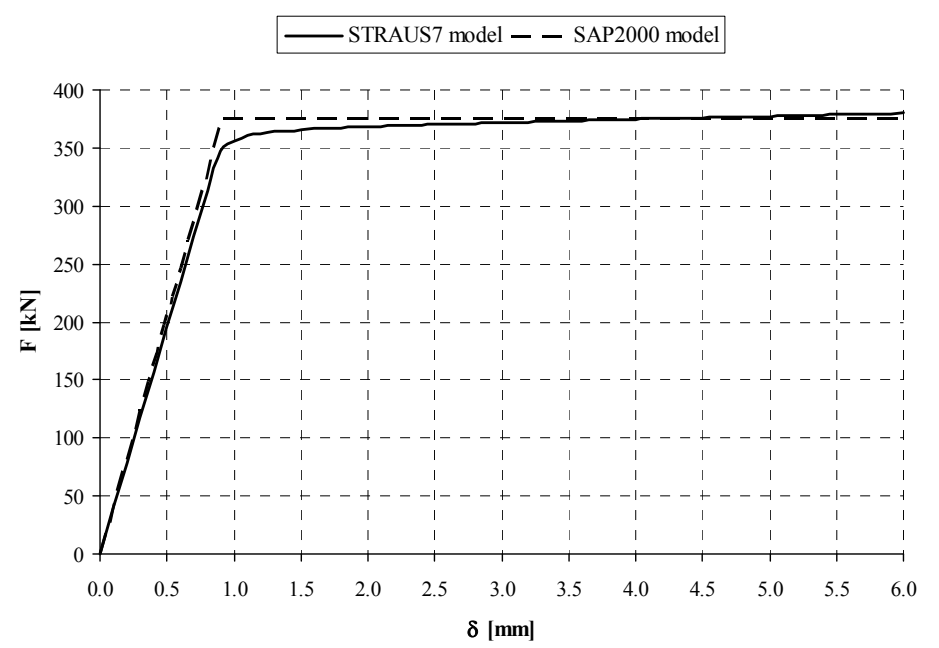

Figure 9. Force-Displacement Curves of the Knee Models

Therefore, by means of Eqs. 39-40, the post-elastic behaviour of a knee element can be modelled by introducing two beam-column elements with plastic hinges at their ends. In particular, an elastic-plastic with strain-hardening bi-linear moment-rotation relationship can be assigned to each plastic hinge. The elastic range develops until the condition $\left(\gamma_{y}, M_{\text {eq.p }}\right)$ is reached, being $\gamma_{y}$ the first yielding rotation, which is calculated as the rotation corresponding to the attainment of the moment $M_{\text {eq.p }}$ at both ends of the member simultaneously. The second branch, accounting for strain-hardening, terminates at the point $\left(\gamma_{u}, M_{\text {eq.u }}\right)$, where $\gamma_{u}$ is the ultimate monotonic rotation, since the monotonic behaviour represents the envelope of the hysteretic cycles. According to the similarity with links of EBFs, the value of 0.2 radians (Engelhardt and Popov [12]) is chosen for the ultimate monotonic deformation of each knee portion.

\section{STATIC AND DYNAMIC NON-LINEAR ANALYSES}

Non-linear analyses have been performed in order to evaluate the seismic response of the designed structures, so that the accuracy of the proposed procedure can be tested. Static and dynamic non-linear analyses have been carried out with different purposes. Static non linear analyses provide useful informations concerning the energy dissipation capacity of each structure and its global ductility. In addition, the pattern of yielding obtained from these analyses can be directly compared with the global failure mode representing the main goal of the proposed design methodology which, even though based on rigid-plastic analysis, operates within the framework of static approaches. As it is well recognised that static approaches do not account for higher mode effects, dynamic non-linear analyses are preferred to predict the actual pattern of yielding for the structure, i.e. the actual collapse mechanism, and the local ductility demands.

Designed KBFs are characterised by the same structural scheme ( 3 bays, with the KBF in the middle one; bay span $L=6 \mathrm{~m}$; knee length $e=1 \mathrm{~m}$; interstorey height $h=3 \mathrm{~m}$, Figure 10) and different number of storeys (from 4 to 10). In particular, with reference to the considered building layout, it is assumed that only KBFs resist to horizontal forces, while all other beams and columns are only able to carry the vertical loads, since all the beam-to-column connections and the column-bases outside of the KB-frame are pinned. 
Nevertheless, the proposed procedure could be extended also to the case of dual systems, in which moment resisting frames are combined with knee braced frames. To this scope, it is sufficient to combine the design procedures developed for each structural typology (Mazzolani and Piluso [1]); this means that the design equations described in the previous Sections have to be updated in order to account for the internal works due to all the beams and the columns, external to the KBF, involved in each mechanism typology. In addition, the axial forces in the columns have to take into account for the contribution of the framed bays, which is significant due to the shear forces transmitted by the beams when plastic hinges are developed at their ends.

However, since both moment resisting frames and knee braced frames are involved in seismic forces absorption, particular care has to be taken in the determination of the respective rates. In fact, as far as the rate of seismic shear acting on the KB-frame increases the dimensioning of knee elements becomes more and more severe, leading to a stronger braced structure. Consequently, the design of a dual system should be obtained by means of a calibration of the seismic shear distribution, in order to obtain an effective seismic response with the minimum structural weight. Researches in this field are currently in progress by the Authors with reference to dual systems constituted by the combination of moment resisting frames and different brace typologies.

With reference to Figure 10, the characteristic values of the vertical loads acting on the floors of the analysed scheme are equal to $3 \mathrm{kN} / \mathrm{m}^{2}$ and $2 \mathrm{kN} / \mathrm{m}^{2}$ for dead and live loads, respectively. The structural material adopted for all the members is S 275 steel grade $\left(f_{y}=275 \mathrm{MPa}\right)$.

The design horizontal forces have been determined according to Eurocode 8, assuming a peak ground acceleration equal to $0.35 \mathrm{~g}$, a seismic response factor equal to 2.5 , a behaviour factor $q$ equal to 6, and an importance factor $\gamma_{I}$ equal to 1.0 (CEN [11]). Therefore, an horizontal force distribution according to the first vibration mode is assumed for the design process. Nevertheless, this assumption does not constitute a restriction of the method. In fact, the design approach could be carried out by means of an iterative process, in which the triangular distribution of horizontal forces represents only the first tentative distribution for dimensioning the structure. Successively, by means of a modal analysis, the vector $\mathbf{F}$ can be updated by means of a combination of the most relevant vibration modes, and the design process can be applied again. However, since dynamic non-linear analyses directly account for the influence of all the vibration modes, the corresponding results provide the actual response of the structure, and they constitute a measure of the accuracy of the proposed procedure even when it is led according to the first eigenmode like in this work.

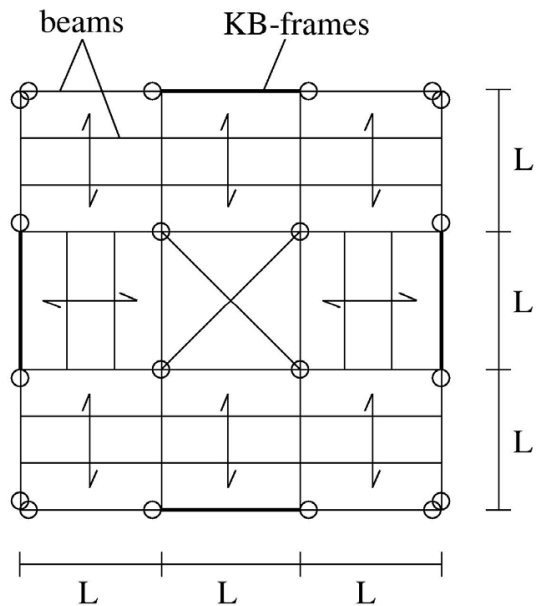

Figure 10. Building Layout 
The design displacement $\delta_{d}\left(\delta_{u}=\delta_{d}\right)$ has been determined as the value corresponding to the maximum allowable engagement of the more involved knee element, i.e. its ultimate rotation $\gamma_{u}$. With reference to Eq. 15, this leads to the following relationship:

$$
\delta_{d}=\theta h_{n_{s}}=\left\{\frac{e_{k} \operatorname{sen} \beta_{k}}{h_{k}-h_{k-1}}\right\}_{\min } \gamma_{u} h_{n_{s}}
$$

where $\gamma_{u}$ is assumed equal to \pm 0.08 rad for short knee in cyclic loading like the case of short links of eccentrically braced frames (Engelhardt and Popov [12]).

For each examined KBF both the scheme with pinned column-to-brace joints and the scheme with continuous column-to-brace joints have been considered (Conti [3]). In this paper, for sake of shortness, only the results concerning 8-storey KBF with pinned brace-to-column joint are presented. In particular, the application of the design procedure described in the previous Sections (with $\delta_{u}=32 \mathrm{~cm}$ ) leads to the standard HEB profiles reported in Table 1 for each member.

Static non-linear analyses have been performed by means of SAP2000. The structure has been modelled by means of non-linear elements with possible plastic hinges located at the ends of each member. In particular columns, diagonals and beams have been modelled using hinges accounting for axial force-bending moment interaction while the shear deformations of each knee portion are accounted for by means of shear hinges. In fact, SAP2000 computer program is supplied with a plastic hinge in pure shear, referred to the local axes of the member, so that the inclination of the knee element with respect to the global reference system is not relevant, and the use of the previously discussed non-linear model in equivalent bending is not necessary. The shear versus plastic displacement diagram has been modelled through a rigid-hardening behaviour. The hardening branch is developed between the values $V_{p}$ and $V_{u}=1.7 V_{p}$, whose corresponding ultimate displacement is given by $\gamma_{u} e / 4$, as obtained by assuming that each plastic hinge is related to an half knee element portion ( 2 plastic hinges both for bottom and top knee portions, 4 plastic hinges for all the member), so that it is related to the half part of the internal work provided by Eq. 37 .

Table 1. 8-Storey KBF - Designed Sections

\begin{tabular}{|c|c|c|c|c|}
\hline storey & Knee & Brace & Beam & Column \\
\hline 1 & HEB 300 & HEB 300 & HEB 160 & HEB 450 \\
\hline 2 & HEB 280 & HEB 300 & HEB 160 & HEB 450 \\
\hline 3 & HEB 280 & HEB 300 & HEB 160 & HEB 400 \\
\hline 4 & HEB 260 & HEB 280 & HEB 160 & HEB 340 \\
\hline 5 & HEB 240 & HEB 280 & HEB 160 & HEB 340 \\
\hline 6 & HEB 220 & HEB 260 & HEB 140 & HEB 300 \\
\hline 7 & HEB 180 & HEB 240 & HEB 140 & HEB 240 \\
\hline 8 & HEB 120 & HEB 180 & HEB 120 & HEB 140 \\
\hline
\end{tabular}

The push-over analyses have been led under displacement control accounting for both mechanical and geometrical non-linearities. Moreover, for each step of the analysis, out-of-plane stability checks for compressed elements have been executed. In Figure 11 the push-over curve and the distributions of plastic hinges for a top-sway lateral displacement both equal and exceeding the design value are reported. These figures underline that according to the goal of the proposed design procedure, yielding occurs for all the knee elements at the design displacement, so that satisfactory energy dissipation capacity and adequate inelastic performances are achieved. Furthermore, the distribution of plastic hinges for displacement values exceeding the design one shows the development of a collapse mechanism of global type. Similar results have been obtained for all the examined KBFs. 
In addition, incremental dynamic non-linear analyses (IDA) have been carried out for the designed KBFs. Dynamic non-linear analyses allow to predict the actual seismic response of the examined structures in terms of actually developed collapse mechanism, energy dissipation capacity and local ductility demands. These analyses have been carried out by means of DRAIN-2DX computer program considering three different seismic motions: two simulated records matching Eurocode 8 inelastic design response spectrum, with $\mathrm{A}$ and $\mathrm{C}$ subsoil class respectively (CEN [11]), and an historical one (Tolmezzo 1976, PGA $=0.313 g$ ). The results coming from these analyses have been post-processed to perform out of plane stability check of the members.

The structure has been modelled as an assembly of non-linear elements characterised through specific hysteretic constitutive laws. In particular columns, braces and beams have been modelled using beam-column elements. For these members the bending moment versus plastic rotation diagram has been modelled through an elastic-perfectly plastic behaviour. The axial force-bending moment interaction domain has been defined according to the plastic domain provided by Eurocode 3 (CEN, 2005). The modelling of knee elements has been carried out, as previously discussed, by means of equivalent plastic hinges in simple bending.

Aiming at the evaluation of the seismic response of the designed KBFs, for each ground motion, the plastic hinge distribution, the maximum absolute and relative displacements and the maximum plastic deformation demands for each structural element have been evaluated. In particular, in order to validate the results provided by the static non-linear analysis, the results concerning 8 -storeys KBF with pinned column-to-brace joint are herein presented. In particular, reference to the Eurocode 8 simulated ground motion for subsoil class A (EC8-A) is made.

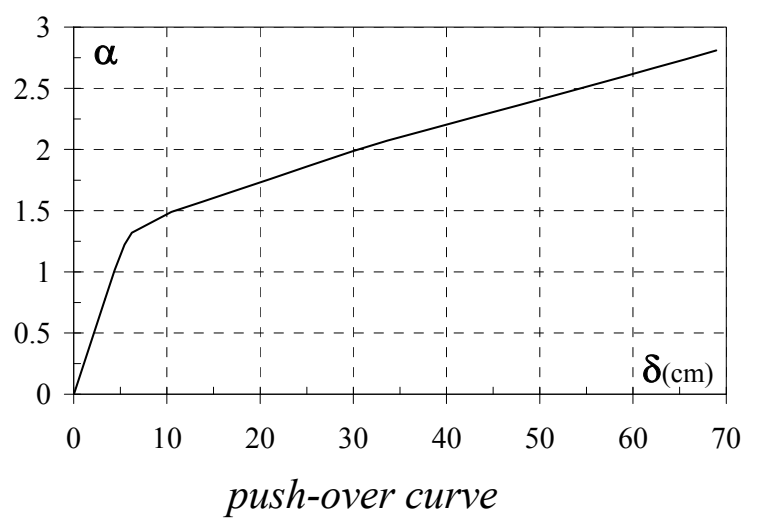

push-over curve
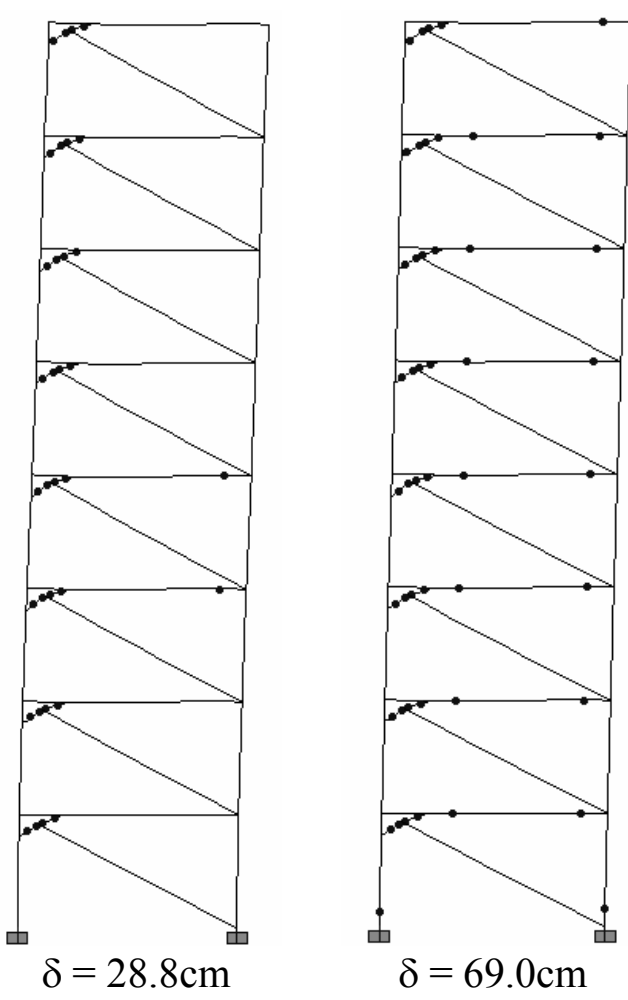

Figure 11. 8-Storeys KBF Push-Over Results 
In Figure 12 the maximum required plastic deformations are reported for increasing values of the peak ground acceleration (PGA). In addition, Figure 13 provides the values of the plastic deformations for all the members (in the figure plastic rotations have to be scaled for the factor $10^{-2}$ ). In Figure 14 the maximum absolute displacements for different values of PGA are depicted in non-dimensional form by means of the roof displacement angle (in symbols $R D A=\Delta / H$ ). In addition, in the same Figure 14 the maximum inter-storey drift ratios are shown (in symbols MIDR $\left.=\delta_{\max } / h\right)$. Similar results have been obtained for all the analysed structures and for all the examined ground motions (showing that the most evident differences in terms of seismic response occur for EC8-C ground motion) and lead to the following observations (Conti [3]).

First of all, the designed structures are characterised by the fulfilment of the design goal, i.e. the development of a collapse mechanism of global type. In fact, the distribution of plastic hinges shows that all the dissipative zones, i.e. all the knee elements, are involved in the collapse mechanism (Figure 13), so that large dissipation capacity and global ductility are achieved. Furthermore, for increasing values of PGA, yielding occurs in the other members (beams and base columns) according to the prediction of the design methodology, and a global collapse mechanism develops.

In addition, regarding local ductility demands, the maximum values of plastic rotations have to be compared with the cyclic local ductility supply provided by short knees (i.e. $\pm 0.08 \mathrm{rad}$ ). With reference to Figure 12, knee elements reach the limit value of $0.08 \mathrm{rad}$ for a PGA value equal to about $1.0 \mathrm{~g}$. Similar results have been obtained for the other analysed structures, where the ultimate knee rotation is reached for high values of PGA (generally between $0.7 g$ and $1.0 g$ ). This result points out that the KBFs designed according to the proposed design procedure are able to withstand severe earthquake exploiting their large global ductility without the fracture of the dissipative zones, unless very high values of PGA are reached. This is a relevant result, since local ductility demands for short members, such as knee elements or short links in EBFs, are adversely affected by the influence of the geometrical configuration.

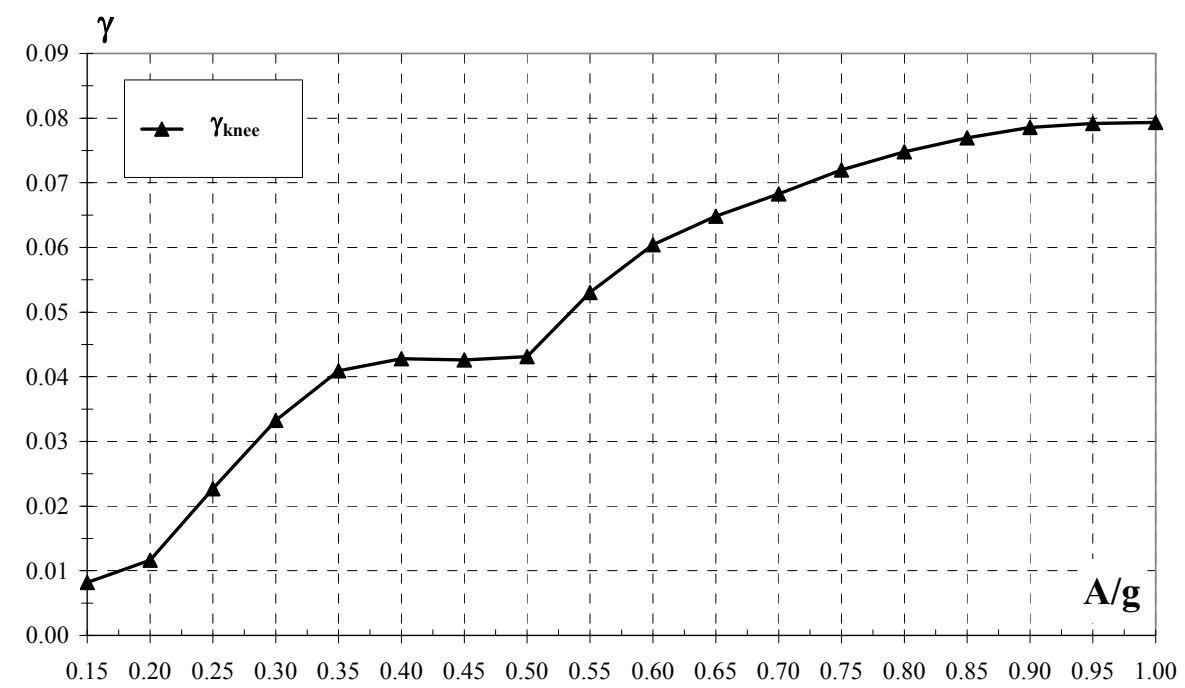

Figure 12. 8-Storeys KBF IDA - Maximum Plastic Knee Deformations (EC8-A)

Finally, it is useful to point out some considerations about the irregular behaviour of the curves depicted both in Figure 12 and in Figure 14. In fact, it is possible to recognize a significant variation of the curve slopes within the PGA range $[0.35 g, 0.55 g]$. First of all it is necessary to underline that not all the analysed structures show the same kind of response, even if several of them are characterised by non-monotonic behaviours. 
It is well known that IDA curves often provide counter-intuitive results, as thoroughly discussed by Vamvatsikos and Cornell [16]. In fact, segments of softening or hardening can be provided after the initial stiffness of the structure, i.e. regions in which the slope of the curve decreases with higher intensity measures or other regions where such slope increases. This means that the structure can experience an acceleration responsible of damage accumulation, but at the following time it is subjected to a deceleration that can be powerful enough to momentarily stop the damage accumulation or even reverse it. So the IDA curve is characterised by lower damage measures and it becomes a non-monotonic function of the PGA. In particular, the examined case is analogous to the case of severe hardening (Vamvatsikos and Cornell [16]). In fact, the system shows an high response for a given intensity level, but exhibits the same or lower response for higher seismic intensities due to excessive hardening. Within this issue, it is the pattern and timing of the accelerogram rather than just the intensity that make the difference. As the earthquake is scaled up, weak response cycles in the early part of the response time-history become amplified enough to generate yielding, so that the structure properties result modified when the stronger cycles are reached. The extreme case of hardening leads to the case in which a structure reaches the global collapse for an intensity measure but not for an higher one, reappearing with high response but still in an equilibrium state. This issue is known as structural resurrection.

\section{CONCLUSIONS}

This paper has been focused on several issues concerning the design of knee braced frames aiming at the attainment of satisfactory seismic performances with the primary goal of developing a collapse mechanism of the global type.

First, the behaviour of knee dissipative zones located in knee elements has been briefly discussed, pointing out the relevant aspects concerning their plastic involvement. These results are particularly useful in the development of a design procedure which is the natural extension to KB-structures of a design methodology already suggested for seismic-resistant frames (Mazzolani and Piluso [1]) and for eccentrically braced frames (Mastrandrea et al. [2]). Therefore, this methodology constitutes a general design approach which allows the control of the failure mode for any type of seismic-resistant structure.

In particular, the procedure starts from the knowledge of the dissipative zones (i.e. knee elements), which are dimensioned in order to resist the internal actions due to the design horizontal loads. Then, according to capacity design, by means of simplified equilibrium equations, the brace cross sections are dimensioned on the basis of the maximum internal actions that the knee elements, at the ultimate limit state, are able to transmit. In addition, the beam cross sections are dimensioned on the basis of the vertical loads acting on the floor. Finally, the column cross sections are obtained by applying the kinematic theorem of plastic collapse (taking into account second order effects due to vertical loads), which allows to derive the design conditions to be satisfied to guarantee a global collapse mechanism for the structure. In addition, in this procedure, a target design displacement of the structure is selected according to the maximum allowable plastic rotation for the dissipative zones, so that also the local ductility demands are under control.

Push-over analyses carried out for an adequate number of designed KBFs have pointed out the goodness of the proposed design procedure. In fact, for all the designed KBFs all the dissipative zones are involved in the collapse mechanism, leading to large global ductility. 
Furthermore, the actual seismic response of the designed KBFs has been studied by means of IDA. The results still show the accuracy of the design procedure, in fact all the designed structures actually exhibit a global mechanism and are characterised by high global ductility and energy dissipation capacity. In addition, the local ductility demands are compatible with the corresponding supplies, even for high PGA values ranging between $0.7 \mathrm{~g}$ and $1.0 \mathrm{~g}$. This means that the proposed procedure is able to control both the collapse mechanism typology and the local ductility demands.
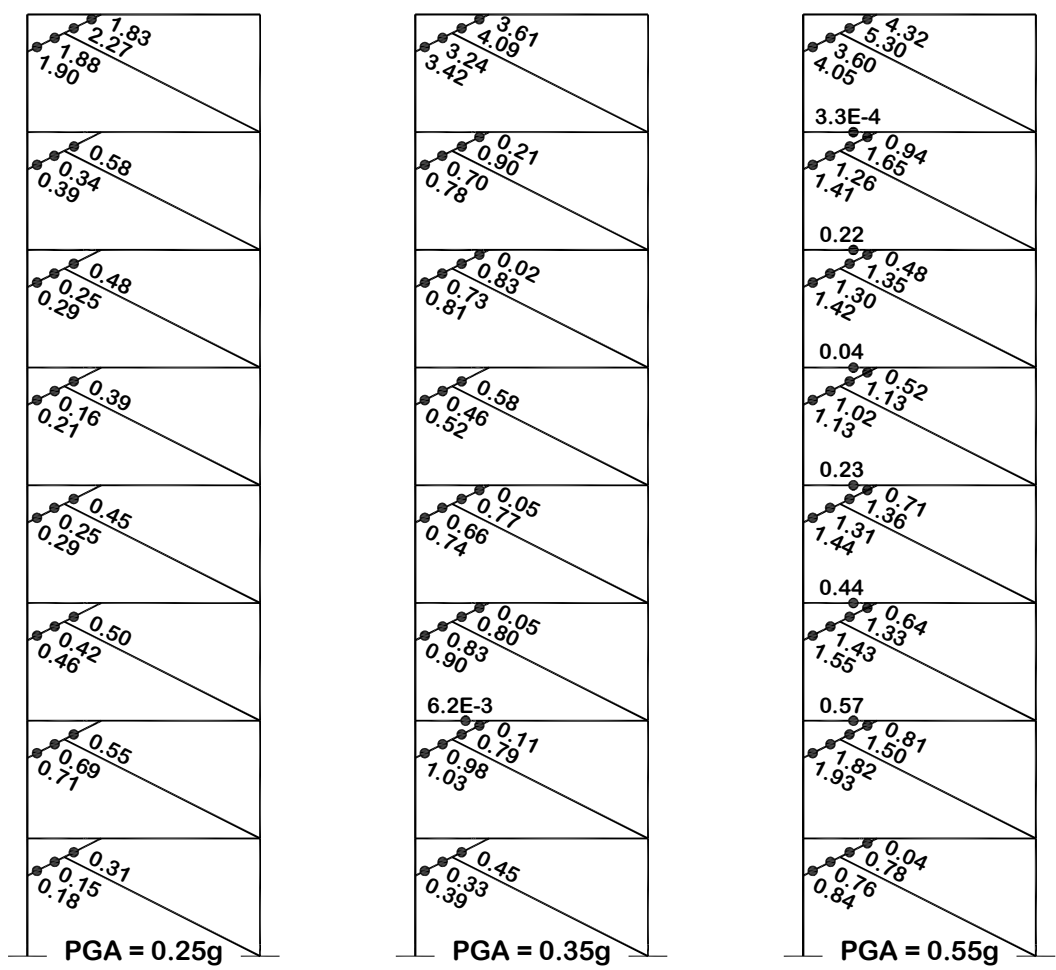

plastic rotations have to be scaled for the factor $10^{-2}$
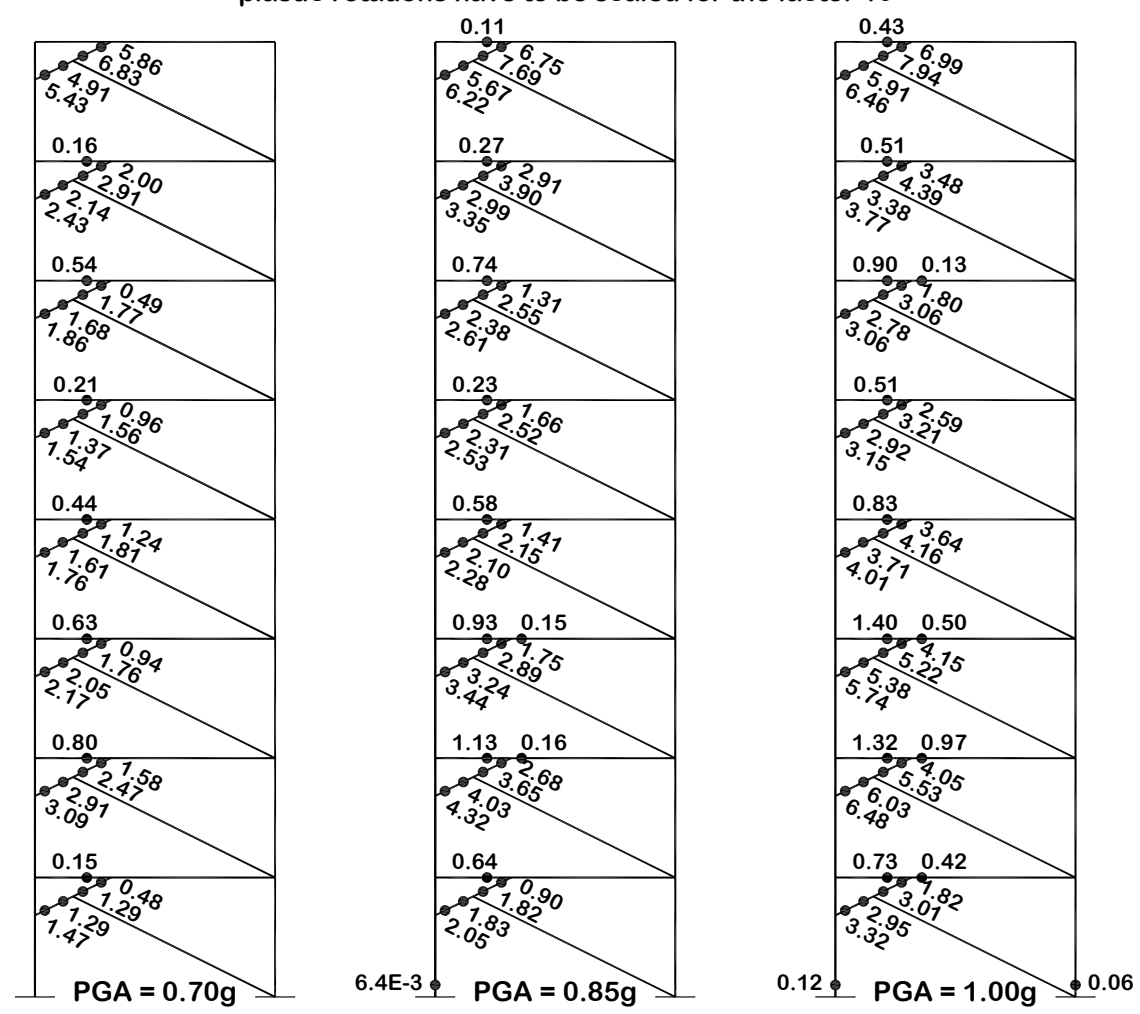

Figure 13. 8-Storeys KBF IDA - Plastic Hinges Envelope (EC8-A) 


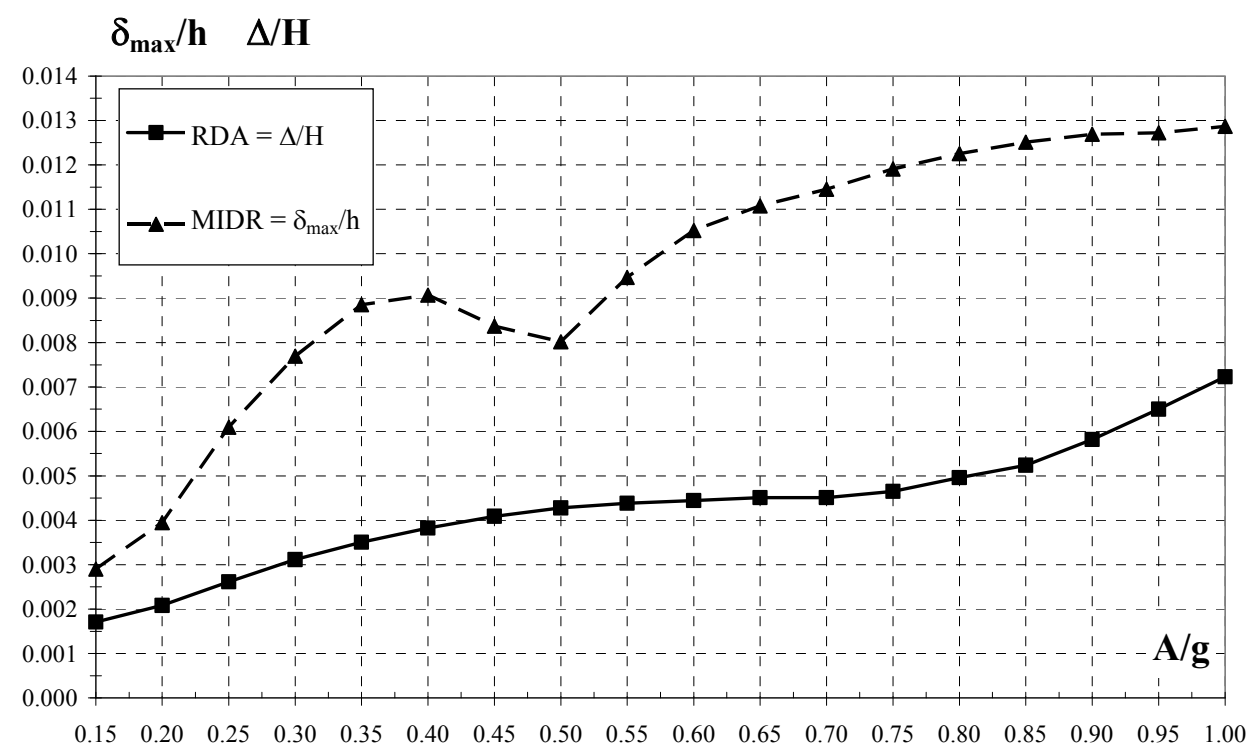

Figure 14. 8-Storeys KBF IDA - Maximum Absolute and Relative Non-Dimensional Displacements (EC8-A)

\section{APPENDIX}

Notation:

- B vector of order $n_{s}$ whose elements $B_{k}$ are equal to the beam plastic moments, reduced for the contemporary presence of the axial force (elements $B_{k}=M_{b, k}$ );

- $\quad \mathbf{B}_{\mathbf{r}} \quad$ vector of order $n_{s}$ whose elements $B_{r k}$ are equal to the diagonal plastic moments, reduced for the contemporary presence of the axial force (elements $B_{r, k}=M_{d, k}$ );

- C matrix of order $n_{c} \times n_{s}$ whose elements $C_{i k}$ are equal to the column plastic moments, reduced for the contemporary presence of the axial force (elements $C_{i k}=M_{c, i k}$ );

- $d_{k} \quad$ distance between the plastic hinge located in the beam (close to the knee) and the first column axis;

- $\quad \mathbf{D}_{\mathbf{v}} \quad$ vector of order $n_{s}$ of the coefficients $D_{v, k}$;

- $D_{v, k} \quad$ coefficient related to the external work of the uniform load acting on the beam of the $k$ th storey (equal to $L d_{k} / 2$ for the examined scheme) (Conti et al. [6]);

- $e_{k} \quad$ length of knee of the $k$ th storey;

- F vector of the design horizontal forces;

- h vector of the storey heights;

- $H_{0} \quad$ sum of the interstorey heights of the storeys involved by the generic mechanism;

- $h_{k} \quad$ storey height of the $k$ th storey;

- $i \quad$ column index;

- $i_{m} \quad$ mechanism index;

- $k \quad$ storey index;

- $\mathbf{K}_{\mathbf{n}} \quad$ vector of order $n_{s}$ whose elements $K_{n k}$ are equal to the knee ultimate shear forces (i.e. $K_{n k}$ $\left.=V_{u, k}\right)$;

- $L$ bay span;

- $M_{c, i k}$ plastic moment, reduced for the presence of the axial internal force, of the $i$ th column of the $k$ th storey;

- $\mathbf{M}_{\mathbf{c k}}$ vector of the plastic moments of the columns of the $k$ th storey, reduced due to the influence of the axial force (elements $M_{c, i k}$ ); 
- $M_{k} \quad$ plastic moment, reduced for the presence of the axial internal force, of the diagonal $\left(M_{d, k}\right)$ or of the beam $\left(M_{b, k}\right)$ of the $k$ th storey;

- $n_{c} \quad$ number of columns for each storey $\left(n_{c}=2\right.$ for one bay KB-frames);

- $n_{s} \quad$ number of storeys;

- $\mathbf{q}$ vector of order $\mathrm{n}_{\mathrm{s}}$ of the uniform loads acting on the beams;

- $q_{k} \quad$ uniform vertical load acting on the beam of the $k$ th storey;

- $\mathbf{R}_{\mathbf{b}} \quad$ vector of order $n_{s}$ of the coefficients $R_{b, k}$;

- $\mathbf{R}_{\mathbf{c}}$ matrix of order $n_{c} \times n_{s}$ of the coefficients $R_{c, i k}$;

- $R_{c, i k} \quad$ coefficient related to the participation of the $i$ th column of the $k$ th storey to the collapse mechanism: $R_{c, i k}=1$ when the element is involved in the mechanism, $R_{c, i k}=0$ in the opposite case;

- $\quad \mathbf{R}_{\mathbf{d}} \quad$ vector of order $n_{s}$ of the coefficients $R_{d, k}$;

- $R_{k} \quad$ coefficient related to the participation of the beam $\left(R_{b, i k}\right)$, knee $\left(R_{k n, i k}\right)$ or diagonal $\left(R_{d, i k}\right)$ of the $k$ th storey to the collapse mechanism: it is equal to plastic deformation of the beam, the knee or the diagonal of the $k$ th storey for a unitary rotation of the KBF columns (Eq. 6-9) when the element is involved in the mechanism, $R_{k}=0$ in the opposite case;

- $\quad \mathbf{R}_{\mathbf{k n}} \quad$ vector of order $n_{s}$ of the coefficients $R_{k n, k}$;

- S shape vector of the storey horizontal virtual displacements;

- V vector of the storey vertical loads, whose $k$ th element $V_{k}$ is the total load acting at the $k$ th storey $\left(V_{k}=q_{k} L\right)$;

- $V_{u, k} \quad$ ultimate shear force of the knee of the $k$ th storey;

- $\beta_{k} \quad$ angle between the direction of the diagonal of the $k$ th storey and the horizontal direction.

\section{REFERENCES}

[1] Mazzolani, F.M. and Piluso, V., "Plastic Design of Seismic Resistant Steel Frames", Earthquake Engineering And Structural Dynamics, 1997, Vol. 26, pp. 167-191.

[2] Mastrandrea, L. and Piluso, V., "Plastic design of eccentrically braced frames: II. Failure mode control", Journal of Constructional Steel Research, Elsevier, ISSN: 0143-974X, doi: 10.1016/j.jcsr.2008.10.001, May 2009, Vol. 65, No. 5, pp. 1015-1028.

[3] Conti, M.A., "Progettazione a Collasso Controllato di Controventi del tipo knee", PhD Thesis (in Italian), University of Salerno, Italy, 2007.

[4] Mazzolani, F.M. and Piluso, V., "Theory and Design of Seismic Resistant Steel Frames", An Imprint of Chapman \& Hall, 1996.

[5] Kasai, K. and Popov, E.P., "General Behavior of WF Steel Shear Link Beams", Journal of Structural Engineering, 1986.

[6] Conti, M.A., Mastrandrea, L. and Piluso, V., "Theoretical Analysis of Moment-Shear Interaction in Knee Braced Frames", Proceedings of Stessa 2006, $5^{\text {th }}$ International Conference on Behavior of Steel Structures in Seismic Areas, Yokohama, Japan, 2006a.

[7] Neal, B.G., "Effect of Shear Force on the Fully Plastic Moment of an I-Beam", Journal of Mechanics and Engineering Science, 1961, Vol. 3, pp. 258-266.

[8] Clement, D.E., "Seismic Analysis of Knee Elements for Steel Frames", PhD Thesis. University of Oxford, England, 2002.

[9] Popov, E.P., Engelhardt, M.D., "Seismic Eccentrically Braced Frames", Journal of Constructional Steel Research, 1988, Vol. 10, pp. 321-354.

[10] Okazaki, T., Arce, G., Ryn, H., Engelhardt, M.D., "Recent Research on Link Performance in Steel Eccentrically Braced Frames", Proceedings of $13^{\text {th }}$ WCEE, Vancouver, Canada, 2004, Paper No. 302. 
[11] CEN, "EN 1998-1:2004 - Eurocode 8: Design of Structures for Earthquake Resistance - Part 1: General Rules, Seismic Actions and Rules for Buildings", Comité Europeén de Normalisation, 2004.

[12] Engelhardt M.D. and Popov E.P., "Behavior of Long Links in Eccentrically Braced Frames", Earthquake Engineering Research Center, University of California, 1989, Report No. $\mathrm{UCB} / \mathrm{EERC}-89 / 01$.

[13] Mastrandrea, L. and Piluso, V., "Plastic design of eccentrically braced frames: I. Moment-shear interaction", Journal of Constructional Steel Research, Elsevier, ISSN: 0143-974X, doi: 10.1016/j.jcsr.2008.10.002, May 2009, Vol. 65, No. 5, pp. 1007-1014.

[14] Conti, M.A., Mastrandrea, L. and Piluso, V., "Plastic Design of Seismic Resistant Knee Braced Frames", Proceedings of Stessa 2006, $5^{\text {th }}$ International Conference on Behavior of Steel Structures in Seismic Areas, Yokohama, Japan, 2006b.

[15] CEN, "EN 1993-1-1:2005 - Eurocode 3: Design of Steel Structures - Part 1-1: General Rules and Rules for Buildings", Comité Europeén de Normalisation, 2005.

[16] Vamvatsikos, D. and Cornell, C.A., "Incremental Dynamic Analysis", Earthquake Engineering And Structural Dynamics, 2002, Vol. 31, pp. 491-514. 